\title{
Workplace design: A powerful tool for supporting employee performance
}

\begin{abstract}
Smart organizations understand that their primary goal is to enhance the performance of their people. In a knowledge work economy, people are the engine that keep companies growing, adapting, improving and innovating. Not surprisingly, thoughtful workplace design can be a powerful tool for supporting employee performance, and a collateral benefit is that what typically supports productivity also enhances employee health and wellness - it's all interrelated. Given the nature of today's work processes, how can the workplace better support human performance? How can the workplace support all of the different activities involved with knowledge work - things like collaboration, creativity, innovation, deep thinking and mentorship? One way to better understand the nature of human performance is through a definition used by organizational psychologists, who believe it is enabled through a blend of ability, motivation and opportunity i.e. performance is a function of the three factors acting together. Ability has to do with whether a person can do a task. Motivation is a measure of whether a person wants to do it. Opportunity is about accessibility; a person can't do a task if she is not given a chance or if she is denied access to necessary resources or amenities. This framework - looking at human performance as being influenced by multiple factors - reflects the difficult and variable nature of our work today. All of these factors must be supported by the work environment in order for people's best work to occur. So, how can the workplace help? According to Judith Heerwagen, a former scientist with the Pacific Northwest National Laboratory who is now a program expert with the General Services Administration, productivity and the workplace are related in these ways: A building can positively affect ability by providing comfortable ambient conditions, by enabling individual control and adjustment of conditions, and by reducing health and safety risks. Negative impacts on ability to do work are associated with conditions that are uncomfortable, distracting, hazardous or noxious. A building can positively affect motivation by providing conditions that promote positive affective functioning, psychological engagement and personal control. Moods create the 'affective context' for thought processes and behaviours and are directly tied to motivation. A building can affect opportunity by providing equitable access to conditions that reduce health and safety risks, equitable access to amenities and compensatory design options where inequities exist and are difficult to eliminate entirely. Which specific workplace strategies provide the right mix of ability, motivation and opportunity to enhance human performance? Best practices in workplace design can help. The paper with the help of secondary data and sources tries to find out the various work design suited to increase the performance of the employees.
\end{abstract}

KEY WORDS : Work design, Employee performance, Productivity

How to cite this paper : Anand, Swati and Saklani, Kailash (2015). Workplace design: A powerful tool for supporting employee performance. Internat. J. Com. \& Bus. Manage, 8(1): 94-101.

\section{MEMBERS OF THE RESEARCH FORUM}

Correspondence to:

SWATI ANAND, School of Management, IMS Unison University, DEHRADUN (UTTARAKHAND) INDIA

Authors' affiliations:

KAILASH SAKLANI, International Institute of Management and Technical Studies, DEHRADUN (UTTARAKHAND) INDIA 